\title{
Superficial mycoses at the Hospital do Servidor Público Municipal de São Paulo between 2005 and 2011*
}

\author{
Nilton Di Chiacchio ${ }^{1}$ \\ Camila Simon Silva ${ }^{4}$
}

\author{
Celso Luiz Madeira ${ }^{2}$ \\ Lucia Helena Gomes Fernandes ${ }^{5}$
}

\author{
Caio Rosa Humaire ${ }^{3}$ \\ Ana Lucia Dos Reis
}

\begin{abstract}
BACKGROUND: Superficial mycoses are fungal infections limited to the outermost layers of the skin. Dermatophytic filamentous fungi and yeasts are the major causative agents of these mycoses. Dermatophytosis is one of the clinical conditions caused by fungal infections most commonly found in dermatological practice. Thus, knowledge of the ecology of dermatophytes provides a better understanding of the natural history of dermatophytosis. Овлестіve: This study aimed to investigate epidemiological and mycological features of superficial mycoses diagnosed from 2005 to 2011 in the Dermatology Clinic of the Hospital do Servidor Público Municipal de São Paulo, Brazil. METHOD: This retrospective study was conducted in the Laboratory of Medical Mycology at the Dermatology Clinic of the Hospital do Servidor Público Municipal de São Paulo. Mycological examinations of 9042 patients with clinical suspicion of superficial mycoses performed between 2005 and 2011 were reviewed. RESULTS: Of 9042 direct microscopic examinations, $2626(29 \%)$ were positive for dermatophytes, $205(2.3 \%)$ were positive for Malassezia, 191 (2.1\%) were positive for other types of yeast, $48(0.5 \%)$ were positive for bacteria, and $5972(66 \%)$ were negative. Mean age of patients was 48 years, $6920(77 \%)$ patients were female and $2112(23 \%)$ were male. ConCLUSION: The biota consisted of six dermatophyte species: T. rubrum, T. mentagrophytes, M. gypseum, T. tonsurans, E. floccosum, and M. canis. The most common site of involvement was the nail and foot in adults and scalp in children, with a female predominance. Both Candida and Malassezia were more prevalent in adult women, the former most commonly affecting the interdigital region and nails and the latter the chest and neck.
\end{abstract}

Keywords: Malassezia; Tinea; Yeasts

\section{INTRODUCTION}

Superficial mycoses are fungal infections limited to the outermost layers of the skin and its appendages. ${ }^{1}$ The chief causative agents of these mycoses are dermatophytes and yeasts.

Dermatophytes are filamentous fungi able to digest and obtain nutrients from keratin and relatively insoluble high-molecular-weight proteins composed of amino acids and peptide bonds that are present in the skin, hair and nails. ${ }^{2}$ There are 39 dermatophyte species divided into three genera: Trichophyton, Microsporum, and Epidermophyton. These species are classified as anthropophilic, geophilic or zoophilic according to their habitat. ${ }^{1,3,4}$ Geophilic dermatophytes are soil-dwelling organisms that grow on human or animal keratin present in the soil or on decomposing keratin sources in the environment; zoophilic organisms are found primarily in animals, while anthropophilic species are primarily associated with humans. ${ }^{1,3}$ Lesions caused by anthropophilic dermatophytes are less inflammatory than those caused by other species. ${ }^{4}$ The distribution of dermatophyte fungi varies from region to region and over time, ${ }^{2,3}$ being influenced by several factors, such as climatic variations, socioeconomic factors, lifestyle, presence of pets, and age. ${ }^{3}$

The most common site of involvement of dermatophytes is the skin and its appendages, and the species that affect the hair rarely affect the fingernails

\footnotetext{
Received on 29.03.2012.

Approved by the Advisory Board and accepted for publication on 18.02.2013.

Study conducted at the Hospital do Servidor Público Municipal de São Paulo (HSPM), São Paulo (SP), Brazil

Conflict of interest: None

Financial funding: None

PhD - Head of the Department of Dermatology, Hospital do Servidor Público Municipal de São Paulo (HSPM), São Paulo (SP), Brazil

Dermatologist - Hospital do Servidor Público Municipal de São Paulo (HSPM), São Paulo (SP), Brazil.

Dermatologist - Hospital do Servidor Público Municipal de São Paulo (HSPM), São Paulo (SP), Brazil

Dermatologist - Private Clinic, São Paulo (SP), Brazil.

Dermatologist - Private Clinic, Brasília (DF), Brazil.

Biologist - Department of Dermatology, Hospital do Servidor Público Municipal de São Paulo (HSPM), São Paulo (SP), Brazil. 
and vice versa. Dermatophyte infections can be further divided according to the affected body site into tinea capitis (scalp), tinea pedis (foot), tinea corporis (body), tinea cruris (groin), tinea manuum (hand), and tinea unguium (fingernail) ${ }^{4,5}$ Dermatophytosis is one of the clinical conditions caused by fungal infections most commonly found in dermatological practice. ${ }^{6}$ Thus, knowledge of the ecology of dermatophytes provides a better understanding of the natural history of dermatophytosis. ${ }^{3}$ The diagnosis of dermatophytosis can be made by direct mycological examination with potassium hydroxide $(\mathrm{KOH}) 10 \%$ of biological material obtained from patients with suspected mycosis, providing results more rapid than fungal cultures, which may take days or weeks. This information, together with clinical history and laboratory diagnosis, ensures that the appropriate treatment is initiated promptly.

Malassezia spp. and Candida spp. are among the yeasts that cause skin infections. Malassezia spp., an agent of superficial mycosis, is strictly lipophilic and part of the normal microbiota of the skin and scalp. ${ }^{3}$ Although without keratinolytic activity, this fungus lives on the skin around the hair and uses epithelial debris or waste products as energy sources for development. ${ }^{1,6}$ This agent is the cause of pityriasis versicolor and has been implicated in the pathogenesis of seborrheic dermatitis. ${ }^{6}$ Candida spp., a yeast component of the normal human microbiota, is considered an opportunistic yeast that compromises, individually or together, mucous membranes, skin and nails. ${ }^{1,6,7}$ This fungus has a worldwide distribution and affects people of all ages, with a preference for certain professionals, such as domestic workers, laundresses, cooks, and nurses. ${ }^{7}$ Several reasons have been suggested to explain the increased incidence of yeast infections in recent decades, including the overuse of antibiotics, immunosuppressants and cytostatic drugs as well as the increasing number of AIDS patients. ${ }^{1,8}$

The recognition of both types of superficial mycoses is of paramount importance due to the great frequency with which they are diagnosed in clinical dermatology. Also, these infections are contagious and responsible for epidemics in some population groups, such as tinea pedis among athletes and tinea capitis in orphanages. ${ }^{1}$

Because superficial mycoses are not notifiable diseases in Brazil, it is difficult to accurately estimate the extent of the problem. This fact reinforces the need for periodic surveys of the frequency of fungal infections and their etiologic agents, including socioeconomic factors and geographic, climate and epidemiological data, in order to develop appropriate prevention and control measures. Thus, it is important to know the species of dermatophytes occurring in a given region over a period of time in order to determine the most common species.

\section{Objective}

This study aimed to investigate clinical, epidemiological and mycological features of superficial mycoses diagnosed from November 2005 to July 2011 in the Dermatology Clinic of the Hospital do Servidor Público Municipal de São Paulo, Brazil.

\section{PATIENTS AND METHODS}

This retrospective study was conducted in the Laboratory of Medical Mycology at the Dermatology Clinic of the Hospital do Servidor Público Municipal de São Paulo, Brazil. Mycological examinations of 9042 patients with clinical suspicion of superficial mycoses performed between November 2005 and July 2011 were reviewed.

Six clinical variants of dermatophytosis were considered: tinea pedis, tinea unguium, tinea corporis, tinea capitis, tinea manuum, and tinea cruris.

Samples were obtained by scraping the scales with a scalpel blade (skin and nails) or removing the hair with hair tweezers. The specimens were cleared using $\mathrm{KOH} \mathrm{20 \%}$ with dimethyl sulfoxide (DMSO), slide-mounted and examined under direct microscopy. Cultures were obtained after seeding on Sabouraud agar and Mycosel agar plates (dermatophytes only). The colonies were identified by visual inspection of plates (macro aspects) and microscopic examination. When necessary, microculture plates and biological tests were used.

\section{RESULTS}

Of a total of 9042 direct microscopic examinations of patients with clinical suspicion of superficial mycoses, 2626 (29\%) were positive for dermatophytes, with hyaline septate hyphae and arthrospores, 205 (2 $3 \%$ ) were positive for Malassezia spp., 191 (2.1\%) were positive for yeasts, $48(0.5 \%)$ were positive for bacteria, and $5972(66 \%)$ were negative. Mean age of patients was 48 years, $6920(77 \%)$ patients were female and $2112(23 \%)$ were male (Table 1$)$.

The mean age of patients positive for dermatophytes $(n=2626)$ was 49 years, $1860(71 \%)$ were female and $766(29 \%)$ were male. Of 2626 dermatophytes isolated, $2426(92.4 \%)$ had positive cultures, and the results were analyzed in this study (Table 2). The dermatophyte species most commonly isolated were T. rubrum (Table 2). The frequency of dermatophytes isolated in relation to different age groups is shown in table 3 . Regarding the number of cases per age group, patients aged 51-60 years accounted for most cases $(n=679,28 \%)$, followed by patients aged $41-50$ years $(n=605,25 \%)$ and patients aged $>60$ years $(n=553,23 \%)$ (Table 4$)$. The most 
frequent subtypes were tinea unguium $(\mathrm{n}=1511$, $62.26 \%)$, tinea pedis ( $\mathrm{n}=617,25.42$ (Table 5).

In cases positive for Candida, the mean age of patients was 50 years, $154(81 \%)$ patients were female and $37(19 \%)$ were male. The interdigital region and nails accounted for 171 (90\%) of cases, and other regions for $20(10 \%)$ of cases. In cases positive for Malassezia, the mean age of patients was 37 years, 125 $(61 \%)$ patients were female and $80(39 \%)$ were male. The chest and neck accounted for $141(69 \%)$ of cases, and other regions for 64 (31\%) of cases.

TABLE 1: Results of 9042 direct microscopic examinations

\begin{tabular}{lllll}
\hline Direct microscopic examination & $\mathbf{N}$ & $\%$ & \multicolumn{2}{c}{$\mathbf{9 5 \%}$ CI } \\
Negative & 5972 & 66.0 & 65.1 & 67.0 \\
Dermatophyte & 2626 & 29.0 & 28.1 & 30.0 \\
Malassezia spp. & 205 & 2.3 & 2.0 & 2.6 \\
Yeast & 191 & 2.1 & 1.8 & 2.4 \\
Bacteria & 48 & 0.5 & 0.4 & 0.7 \\
Total & $\mathbf{9 0 4 2}$ & $\mathbf{1 0 0}$ & & \\
\hline $\mathbf{9 5} \% \mathbf{C I}=\mathbf{9 5} \%$ confidence interval & & &
\end{tabular}

TABLE 2: Dermatophyte species isolated (positive cases) absolute and relative numbers and confidence interval

\begin{tabular}{lllll}
\hline Dermatophyte species & N & $\%$ & \multicolumn{2}{c}{$\mathbf{9 5 \% \mathbf { C I }}$} \\
T. rubrum & 2333 & 96.2 & 96.0 & 96.9 \\
T. mentagrophytes & 57 & 2.3 & 2.3 & 3.0 \\
M. gypseum & 15 & 0.6 & 0.6 & 0.9 \\
T. tonsurans & 8 & 0.3 & 0.3 & 0.6 \\
E. floccosum & 7 & 0.3 & 0.3 & 0.5 \\
M. canis & 6 & 0.2 & 0.2 & 0.4 \\
Total & $\mathbf{2 4 2 6}$ & $\mathbf{1 0 0}$ & & \\
\hline $\mathbf{9 5} \% \mathbf{C I}=\mathbf{9 5 \%}$ confidence interval & & & \\
\hline
\end{tabular}

\section{DISCUSSION}

Dermatophytosis remains a common clinical condition in humans worldwide. Factors such as weather conditions, social practices, and hygiene practices certainly contribute to the epidemiological variations in dermatophytes.

When all dermatophyte species isolated from 2426 dermatophyte-positive cultures were analyzed, the predominance of T. rubrum followed the international and national trends and this agent was also the most frequent across all age groups (Table 3). ${ }^{2,-13}$ This fungus is considered a major etiologic agent of dermatophytosis, most likely representing the profile of the urban dermatophyte microbiota, followed by $\mathrm{T}$. mentagrophytes, M. gypseum, T. tonsures, E. floccosum, and M. canis. $2,9,10-12,14$

The anatomical site most commonly infected with dermatophytes was the nails, accounting for $62.26 \%$ of cases, which is consistent with studies in the literature. ${ }^{1,2,79,15}$ The region of the foot ranked second as a site of involvement, accounting for $25.42 \%$ of cases, in agreement with previous studies. ${ }^{1,2,9,15,16}$ However, some studies have reported the feet as the anatomical site most frequently affected by dermatophytosis. ${ }^{3,10,11,17,18}$ Ranking third we found dermatophytosis of the body with $6.26 \%$ of cases, in accordance with the published literature, ${ }^{1,2,3,10,17}$ followed by the inguinal region $(3.42 \%)$, hand $(1.65 \%)$, and scalp $(0.99 \%)$.

In children aged $\leq 10$ years, the most frequent site was the scalp, corroborating data from previous studies, with $22(42.59 \%)$ cases of tinea capitis, 14 $(63.6 \%)$ of them caused by M. gypseum, $6(27.3 \%)$ caused by T. tonsurans, and $2(9.1 \%)$ caused by $\mathrm{M}$. canis. ${ }^{1,10,17,19}$ Tinea capitis is a disease of childhood and its progression can vary from an acute to a chronic form. Therefore, understanding the epidemiology and ecology of tinea capitis in a particular country is

TABLE 3: Absolute and relative frequency of dermatophytes isolated by age group in 2426 positive cases

\begin{tabular}{|c|c|c|c|c|c|c|c|c|c|c|c|c|c|c|}
\hline Dermatophyte species by age & $0-1$ & & $11-2$ & & & 21-30 & & $31-40$ & $41-5$ & & $51-6$ & & $>60$ & \\
\hline$p=0.0003$ & $\mathrm{n}$ & $\%$ & $\mathbf{n}$ & $\%$ & n & $\%$ & n & $\%$ & $\mathbf{n}$ & $\%$ & $\mathbf{n}$ & $\%$ & $\mathbf{n}$ & $\%$ \\
\hline T. rubrum & 27 & 51.92 & 110 & 95.65 & 124 & 98.41 & 300 & 98.68 & 565 & 95.76 & 658 & 97.63 & 549 & 97.17 \\
\hline T. mentagrophytes & 2 & 3.85 & 2 & 1.74 & 1 & 0.79 & 4 & 1.32 & 23 & 3.90 & 15 & 2.23 & 10 & 1.77 \\
\hline M. gypseum & 14 & 26.92 & 0 & 0.00 & 0 & 0.00 & 0 & 0.00 & 0 & 0.00 & 1 & 0.15 & 0 & 0.00 \\
\hline T. tonsurans & 6 & 11.54 & 0 & 0.00 & 0 & 0.00 & 0 & 0.00 & 1 & 0.17 & 0 & 0.00 & 1 & 0.18 \\
\hline E. floccosum & 0 & 0.00 & 1 & 0.87 & 1 & 0.79 & 0 & 0.00 & 1 & 0.17 & 0 & 0.00 & 4 & 0.71 \\
\hline M. canis & 3 & 5.77 & 2 & 1.74 & 0 & 0.00 & 0 & 0.00 & 0 & 0.00 & 0 & 0.00 & 1 & 0.18 \\
\hline TOTAL & 52 & 100 & 115 & 100 & 126 & 100 & 304 & 100 & 590 & 100 & 674 & 100 & 565 & 100 \\
\hline
\end{tabular}


TABLE 4: Absolute and relative frequency of dermatophytosis isolated by age group and subtype

\begin{tabular}{|c|c|c|c|c|c|c|c|c|c|c|c|c|c|c|c|c|}
\hline \multirow[t]{2}{*}{$\mathrm{p}<0.0001$} & \multicolumn{2}{|c|}{$0-10$} & \multicolumn{3}{|c|}{$11-20$} & \multicolumn{2}{|l|}{$21-30$} & \multirow{2}{*}{$\begin{array}{l}31-40 \\
\%\end{array}$} & \multicolumn{2}{|c|}{$41-50$} & \multicolumn{2}{|c|}{$51-60$} & \multicolumn{2}{|l|}{$>60$} & \multicolumn{2}{|c|}{ TOTAL } \\
\hline & $\mathbf{n}$ & $\%$ & $\mathbf{n}$ & $\%$ & $\mathbf{n}$ & $\%$ & $\mathbf{n}$ & & $\mathbf{n}$ & $\%$ & $\mathbf{n}$ & $\%$ & $\mathbf{n}$ & $\%$ & $\mathbf{n}$ & $\%$ \\
\hline Tinea unguium & 11 & 20.37 & 40 & 38.10 & 66 & 49.25 & 188 & 63.30 & 384 & 63.74 & 448 & 65.98 & 374 & 67.63 & 1511 & 62.26 \\
\hline Tinea pedis & 9 & 16.67 & 42 & 40.00 & 48 & 35.82 & 83 & 27.95 & 159 & 26.28 & 162 & 23.86 & 114 & 20.61 & 617 & 25.42 \\
\hline Tinea corporis & 11 & 20.37 & 14 & 13.33 & 7 & 5.22 & 17 & 5.72 & 32 & 5.29 & 40 & 5.89 & 31 & 5.61 & 152 & 6.26 \\
\hline Tinea cruris & 0 & 0.00 & 6 & 5.71 & 9 & 6.72 & 7 & 2.36 & 20 & 3.31 & 20 & 2.95 & 21 & 3.80 & 83 & 3.42 \\
\hline Tinea manuum & 0 & 0.00 & 2 & 1.90 & 4 & 2.99 & 2 & 0.67 & 10 & 1.65 & 9 & 1.33 & 13 & 2.35 & 40 & 1.65 \\
\hline Tinea capitis & 22 & 42.59 & 1 & 0.95 & 0 & 0.00 & 0 & 0.00 & 0 & 0.00 & 0 & 0.00 & 0 & 0.00 & 23 & 0.99 \\
\hline TOTAL & 53 & 100 & 105 & 100 & 134 & 100 & 297 & 100 & 605 & 100 & 679 & 100 & 553 & 100 & 2426 & 100 \\
\hline
\end{tabular}

TABLE 5: Frequency of dermatophytosis

\begin{tabular}{lll}
\hline & Total & \\
& $\mathbf{N}$ & $\%$ \\
Tinea unguium & 1511 & 62.26 \\
Tinea pedis & 617 & 25.42 \\
Tinea corporis & 152 & 6.26 \\
Tinea cruris & 83 & 3.42 \\
Tinea manuum & 40 & 1.65 \\
Tinea capitis & 23 & 0.99 \\
\hline TOTAL & $\mathbf{2 4 2 6}$ & $\mathbf{1 0 0 . 0 0}$ \\
\hline
\end{tabular}

important for educational and sanitary purposes and for the development of screening guidelines for detection of infectious foci and adoption of preventive measures. ${ }^{20}$ Among individuals aged $11-20$ years, tinea pedis was most frequent, accounting for $42(40 \%)$ of cases. ${ }^{3,10}$ In all other age groups, tinea unguium was the most prevalent subtype.

The mean patient age in dermatophyte-positive cases was 49 years, and dermatophytosis was more frequently found in individuals over 40 years of age, with a female predominance $(n=1860,71 \%)$ consistent with previous studies. ${ }^{1,4,10,19}$

Pityriasis versicolor is a superficial mycosis caused by Malassezia that has a cosmopolitan distribution, occurring mainly in temperate and tropical climates. It is associated with several factors including poor health status, chronic infections, excessive sweating, and physiological states such as pregnancy, contraceptive use, and steroid therapy. ${ }^{21}$

In this study, most cases of Malassezia infection occurred in adulthood (mean patient age, 37 years). A possible explanation is that, because of the lipophilic nature of this yeast and the post-puberty hormonal stimulus inherent in this age group, there is stimulation of sebaceous glands accompanied by an increase in the fat content of the skin, which serves as a sub- strate for the fungus. These results are in agreement with the literature. ${ }^{21-24}$ The most common sites were the chest and neck, with 141 (69\%) cases, and other regions accounting for $64(31 \%)$ of cases. This is probably due to the fact that these are the regions with the highest concentration of sebaceous glands, which is in agreement with data from previous studies. ${ }^{21,22}$ Men and women are about equally affected. ${ }^{22,23}$ In this study, 125 (61\%) affected patients were female and $80(39 \%)$ were male, which is also consistent with data from the literature reporting a variation in this prevalence, with some studies pointing toward male predominance ${ }^{24,25}$ and others toward female predominance. ${ }^{21,26}$

Candida is a normal component of the human microbiota, being considered an opportunistic yeast that compromises, individually or together, mucous membranes, skin and nails. ${ }^{16,7}$ As an agent of superficial mycoses, it has the ability to digest keratin present in the skin and its appendages, which may trigger an inflammatory host response. ${ }^{1}$ Among cases positive for Candida, the mean age of patients was 50 years, and $154(81 \%)$ patients were female and $37(19 \%)$ were male. The interdigital region and nails accounted for $171(90 \%)$ of cases, and other regions for $20(10 \%)$ of cases, which is consistent with the literature..$^{15,27-30}$

\section{CONCLUSION}

In this study, the biota consisted of six dermatophyte species, T. rubrum, T. mentagrophytes, M. gypseum, T. tonsurans, E. floccosum, and M. canis, maintaining the trend of increased frequency of T. rubrum and stable values for $\mathrm{T}$. mentagrophytes over time. The most common site of involvement was the nail and foot in adults and scalp in children, with a female predominance.

Both Candida and Malassezia were more prevalent in adult women, the former most commonly affecting the interdigital region and nails and the latter the chest and neck. $\square$ 


\section{REFERENCES}

1. Oliveira JAA, Barros JA, Cortez ACA, Oliveira JSRL. Superficial mycoses in the City of Manaus/AM between March and November/2003. An Bras Dermatol. 2006;81:238-43.

2. Aquino VR, Constante CC, Bakos L. Frequency of dermatophytosis in mycologica examinations at a general hospital in Porto Alegre, Brazil. An Bras Dermatol. 2007; 82:239-44

3. Ruiz LRB, Zaitz C. Dermatophytes and dermatophytosis in the city of São Paulo, from August 1996 to July 1998. An Bras Dermatol. 2001:76:391-401.

4. Lima EO, Pontes ZBV, Oliveira NMC, Carvalho MFFP, Guerra MFL, Santos JP. Dermatophytosis frequency in Joäo Pessoa - Paraíba - Brazil. An Bras Dermatol. 1999;74:127-32

5. Andrews MD, Burns M. Common tinea infections in children. Am Fam Physician 2008;77:1415-20

6. Sanabria R, Fariña N, Laspina F, Balmaceda MA, Samudio M. Dermatofitos y hongos leveduriformes produtores de micosis superficiales. [acesso 05 jan.2004]. Disponível em: http://www.una.py/iics/TEMA12.pdf.

7. Campanha AM, Tasca RS, Svidzinski TIE. Dermatomicoses: freqüência diagnóstico laboratorial e adesão de pacientes ao tratamento em um sistema público de saúde, Maringá-PR, Brasil. Lat Am J Pharm. 2007;26:442-8.

8. Brilhante RS, Paixão GC, Salvino LK, Diógenes MJ, Bandeira SP, Rocha MF, et al. Epidemiology and ecology of dermatophytoses in the City of Fortaleza: Trichophyton tonsurans as important emerging pathogen of Tinea capitis. Rev Soc Bras Med Trop. 2000;33:417-25

9. Arantes TD, Wille MP, Silva, JLM. Epidemiologia das dermatomicoses em população da periferia de Araraquara - SP. Rev Bras Clin Med. 2009;7:295-8.

10. Costa TR, Costa MR, da Silva MV, Rodrigues AB, Fernandes Ode F, Soares AJ, et al Etiologia e epidemiologia das dermatofitoses em Goiânia-Go. Rev Soc Bras Med Trop. 1999;32:367-71

11. Rezende C, Borsari GP, Silva ACF, Cavalcanti RR. Estudo epidemiológico das dermatofitoses em instituicões da cidade de Barretos, São Paulo, Brasil. Rev Bras Anal Clin. 2008:40:13-16

12. Soon SH, Adam B. The isolation of Dermatophytes at the university hospital Malaysian J Path. 1978:1:85-9.

13. $\mathrm{Ng} \mathrm{KP}$, Soo-Hoo TS, Na SL, Ang LS. Dermatophytes isolated from patients in University Hospital, Kuala Lumpur, Malaysia. Mycopathologia. 2002;155:203-6.

14. Aghamirian MR, Ghiasian SA. Onychomycosis in Iran: epidemiology, causative agents and clinical features. Nihon Ishinkin Gakkai Zasshi. 2010;51:23-9.

15. Pelegrini A, Takahashi JP, Pereira Cde Q, Pessoni RB, Souza MC. Incidence of dermatophytosis in a public hospital of São Bernardo do Campo, São Paulo State, Brazil. Rev Iberoam Micol. 2009;26:118-20.

16. Ellabib MS, Khalifa ZM. Dermatophytes and other fungi associated with skin mycosis in Tripoli, Libia. Ann Saudi Med. 2001;21:193-5.

17. Reis CMS, Gaspar APA, Gaspar NK, Leite RMS. Estudo da flora dermatofítica na população do Distrito Federal. An bras Dermatol 1992;67:103-11

18. Mazón A, Salvo S, Vives R, Valcayo A, Sabalza MA. Estudio etiológico y epidemiológico de las dermatofitosis en Navarra. Rev Iberoam Micol. 1997;14:65-8.
19. Fernandes NC, Akiti T, Barreiros MG.. Dermatophytoses in children: study of 137 cases Rev Inst Med Trop Sao Paulo. 2001;43:83-5..

20. Marques AS, Camargo RMP, Fares AHG, Takashi RM , Stolf HO. Tinea capitis: epidemiological and ecological aspects of cases observed from 1983 to 2003 in the Botucatu Medical School, state of São Paulo-Brazil. An Bras Dermatol. 2005;80:597-602.

21. Furtado MSS, Cortez ACA, Ferreira JA. Pitiríase versicolor em Manaus,Amazonas- Brasil. An Bras Dermatol. 1997:72:349-351.

22. Trope BM, Assis TL, Marques AS. Pitiríase versicolor - Atualização bibliográfica. An Bras Dermatol.1992:67:159-66

23. Oliveira JR, Mazocco VT, Steiner D. Pitiríase Versicolor. An Bras Dermatol. 2002:77:611-8

24. Hellgren L, Vincent J.. the incidence of Tinea Versicolor in central Sweden. J Med Microbiol. 1983;16:501-2.

25. Mahmoudabadi AZ, Mossavi Z,Zarrin M. Pityriasis versicolor in Ahvaz, Iran. JJM 2009;2:92-6

26. Tarazooie B, Kordbacheh P, Zaini F, Zomorodian K, Saadat F, Zeraati H, et al. Study of the distribution of Malassezia species in patients with pityriasis versicolor and healthy individuals in Tehran, Iran. BMC Dermatol. 2004;4:5.

27. Crocco El, Mimica LMJ, Muramatu LH, Garcia C, Souza VM, Ruiz LRB, Zaitz C. Identification of Candida species and antifungal susceptibility in vitro: a study on 100 patients with superficial candidiasis. An Bras Dermatol. 2004:79:689-97.

28. Mahmoudabadi AZ. Clinical characteristics and mycology of cutaneous candidiasis in Ahwaz (Iran). Pak J Med Sci. 2006:22:43-6.

29. Tan HH. Superficial fungal infections seen at the national skin centre, Singapore. Nihon Ishinkin Gakkai Zasshi. 2005;46:77-80.

30. Rahbar M, Mehrabani HG, Dahim P, molanei S, Roodaki MMA. Prevalence and Etiologica Agents of Cutaneous Fungal Infections in Milad Hospital of Tehran, Iran. Egy Dermatol online J. 2010:2:3

MAILING ADDRESS:

Caio Rosa Humaire

Rua Castro Alves, 60 - 5 andar sala 52 - Liberdade

Brazil

E-mail:crhumaire@hotmail.com

How to cite this article: Di Chiacchio N, Madeira CL, Humaire CR, Silva CS, Fernandes LHG, Reis AL. Superficial mycoses at the Hospital do Servidor Público Municipal de São Paulo between 2005 and 2011. An Bras Dermatol. 2014;89(1):67-71. 